\title{
THE ROLE OF INDIVIDUAL HUMAN POTENTIAL IN THE SPACE OF THE UNIVERSAL ONE
}

\author{
V. Kirko', A. Lukyanova², V. Razumovskaya ${ }^{3}$, E. Grishaeva3 \\ ${ }^{1}$ Siberian Federal University, Krasnoyarsk State Pedagogical University named after V.P. \\ Astafyev (RUSSIAN FEDERATION) \\ ${ }^{2}$ Krasnoyarsk State Pedagogical University named after V.P. Astafyev, Reshetnev Siberian \\ State University of Science and Technology (RUSSIAN FEDERATION) \\ ${ }^{3}$ Siberian Federal University (RUSSIAN FEDERATION)
}

\begin{abstract}
In the understanding of the present paper's authors the individual human potential (IHP) is considered as upbringing, education, health, talent, skills and abilities that are directly inherent of a person. IHP is fully disclosed in the space of human capital and is an element of the universal potential. In the human life cycle the IHP changes daily and resembles the change in stock quotes of companies on the stock exchange. Each day it can increase and decrease depending on the inspiration, physical and psychological health, and its level changes in the context of education and knowledge received at the moment.
\end{abstract}

In the time aspect the IHP is limited by the life cycle of a person and can have various trends continuously increasing, stabilizing, decreasing, and abruptly changing (a sharp increase or decrease). The continuously increasing trend is mainly provided by education accompanied with a stabilizing health factor. The second (stabilizing one) implies the lack of a person's desire to increase his/her IHP or the limitation of external factors. The third (decreasing one) may be associated with a gradual loss of mental or psychological health or the gradual influence of the environment. The last trend (abruptly changing one) is associated with a sharp increase in its capabilities. This is either a transition to another level of education or a sharp change in the surrounding socio-economic paradigm (i.e., the possibility of using a larger amount of human capital). Changes to the IHP may have limitations caused by the external reasons such as: legislative, moral, ethical, political, ethnic, etc.

Despite the fact that IHP has a limited life cycle, the human potential (capital) increases in time perspective primarily due to the increase of the accumulated by the mankind knowledge, skills and abilities, as well as due to the constant population increase. The paper deals with the issue of the essential difference between the universal human potential and human capital. It is proved that the human potential can change abruptly, which can be caused by epoch-making discoveries and inventions, socio-economic, political changes, as well as environmental disasters. In contrast to the potential, the accumulated universal capital changes from the abovementioned reasons, i.e. it must take some time for the potential to pass into the capital.

The main engine of this transition is the individual human potential. The paper deals with the formation of the structure of human potential and capital. It is shown that the structure is of discrete nature and is formed by merging and combining IHP in various industrial, social, national and supranational forms to achieve certain results and achievements (industrial, social, political, scientific, etc.).

The paper also presents the results of research on the formation of IHP in high school students of the Arctic zone of Eastern Siberia living in locally isolated settlements, as well as the abrupt change in their IHP at a sharp change in socio-economic conditions. The results of their adaptation are demonstrated.

Keywords: individual human potential, human capital, life cycle, high school students of the Arctic zone of Eastern Siberia.

\section{INTRODUCTION}

The individual human potential (IHP) is featured as a polyvalent concept related to a person with a set of attributed elements such as upbringing, education, health, talent, skills, abilities and inspiration as well. These specific qualities reflect the inner nature of a person. Thus, IHP being a complex phenomenon converts its individual potential into a core element of the universal potential. The transition goes via the human capital track. 
In Shultz's formulation, human capital is a complex of knowledge, skills and competences that are used for satisfaction of varied needs both of a person and of society [1]. Since then scholars including Becker, Korchagin and others have been gradually developing the interpretation of this phenomenon in question [2-3].

As it was mentioned above, in the human life cycle the IHP is under constant change and resembles the volatility in stock quotes of oil and gas companies on the stock exchange [4].

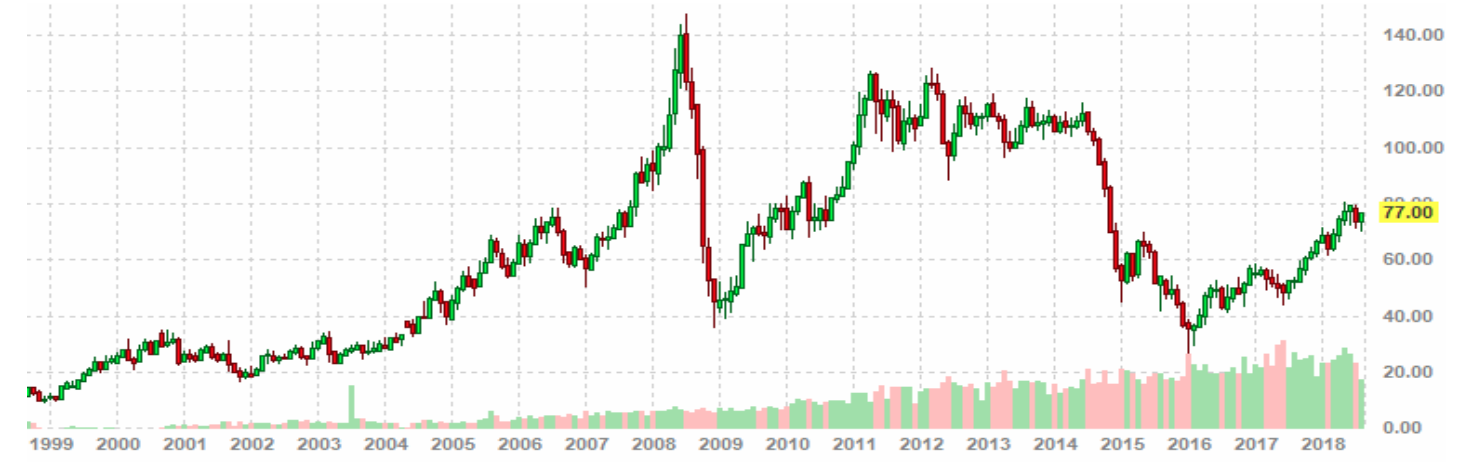

Fig.1. Oil (Brent) price dynamics

The figure shows daily IHP rhythm fluctuations of oil prices. Similarly, in logic of many scholars IHP can be compared with the oil price dynamics. Therefore, IHP can increase and decrease daily and even hourly in reply to physical, mental, psychological or inspirational condition of a person. Accordingly, its level depends on their knowledge, educational background and talent.

IHP specific properties are:

- The life cycle of a person restricts IHP longevity;

- Individual rhythms show different conditions: gradually increasing, stabilizing, decreasing and intermittent (abruptly changing).

The gradually increasing one is habitually provided by a higher level of education along with a stabilizing health factor. The second one, i.e. a stabilizing trend features a lack of emotional inspiration or possibility to increase IHP due to restricting external factors. The third one, a decreasing trend can be linked to either gradual loss of psychological or mental health or destructive environmental impact on people when they accidently are placed in the negatively charged zone of the human capital [5]. The intermittent upward trend is connected with a sharp growth of opportunities of a person, e.g. due to the higher level of education and the change of the social or economic paradigms. In other words, a person can use a bigger capacity of the universal human potential. Moreover, the IHP fluctuation can be limited to and explained by a set of external factors such as legislative, political, ethical and ethnic ones.

\section{METHODOLOGY}

Human capital has been explored from many points of view. There are works addressing many strands, encapsulating insights from economics, psychology, sociology and pedagogical science. Under closer observance there are topicalities such as "Investment in human capital" and "Humancapital approach to entrepreneurship", and many others.

Our aim is to understand the relationship between the individual human potential and the universal one. The paper synthesizes results of the longitudinal research conducted by a team of colleagues from Siberian Federal University and Krasnoyarsk State Pedagogical University named after V.P. Astafyev. Scholars had been working in the Northern parts of the Krasnoyarsk Krai and The Republic of Sakha Yakutia.

Previous projects accumulated materials manifesting and modelling typical changes of the individual human capital of preschool age children and high school students. Variants of their individual capital changes were taken into consideration under external factors impact. 
We also used contrastive and typological methods to show the influence of different so called "Ways of Technology" on logical schemes of interconnectedness between universal potential and the capital.

\section{RESULTS}

At the preschool and school education level, there are a lot of conditions aiming on equal and multicentred IHP development. Its specific features are targeted and personalized according to the children's natural gifts and their preferences. Additional prerequisites such as extra curriculum activities options come on stage as well.

The abovementioned results are proven by a series of previous research dedicated to high school students residing in remote areas of the Northern and Arctic territories of the Krasnoyarsk Krai (a Federal subject of Russia) and the Republic of Sakha Yakutia (Far Eastern Federal District of the Russian Federation). The residents of remote localities and settlements are indigenous ethnic population. They are hunters, fishermen and reindeer herders.

The survey examined high school students (600 in a total amount) [6;7;8]. Complex physiological and psychological researches $[9 ; 10]$ evidenced the fact that at this life cycle stage their IHP and the level of adaptation to external social and economic conditions practically do not depend on either their ethnicity or climate zone. Despite severe weather conditions, schoolchildren are physiologically in a good health and adaptive to external social and economic conditions.

The figure 2 testifies logistic curves of five optional scenarios for IHP development of school students residing in isolated and remote areas. (The authors anticipate similar scenarios that might be characteristic for other settlements in different territories of the Russian Federation and other countries).

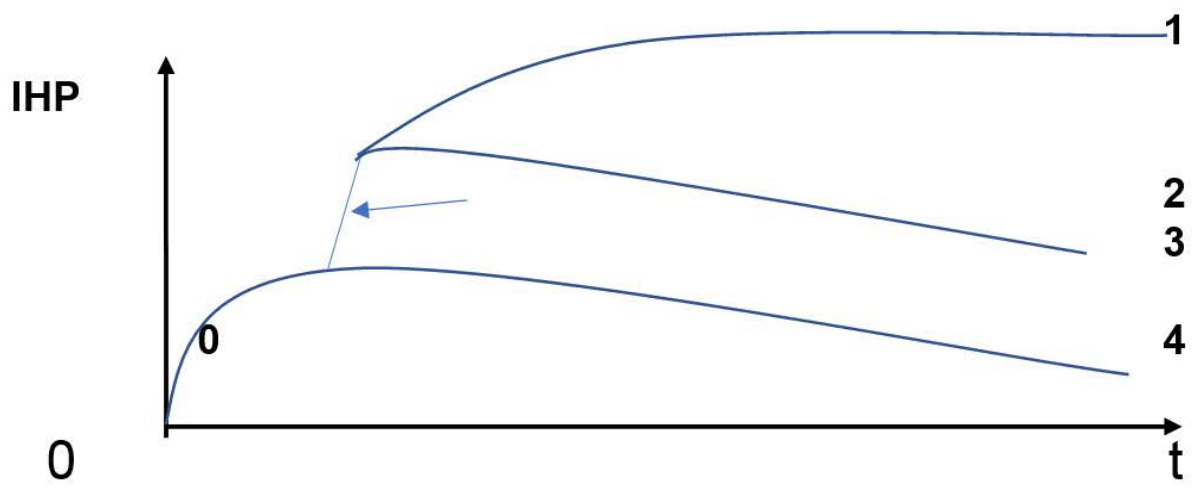

Fig. 2. Logistic curves of optional scenarios of the IHP development of school students residing in isolated localities.

The interpretation of the Figure is the following: $t$ - time; 0 - initial scenario for preschool and school education; 1 and 2 - scenarios that indicate sharp change of the social and economic paradigm and further increasing (due to the higher level of education) or decreasing (due to IHP striking a negative capital zone); 2 - retention and keeping going of traditional activities in taiga or tundra for nomadic indigenous population; 4 - a gradual degradation scenario due to unemployment and alcoholism [5]. Apparently, the latter scenario leads to a rather high criminal level, suicides or poor health conditions in the Northern territories causing shorter lives (not longer than 50 years of age) [11].

\section{CONCLUSIONS}

Despite the fact that IHP has a limited life cycle, it is a core element of the universal potential. The universal potential has a similar property with capital itself; it tends to increase due to a growing level of accumulated knowledge, skills and competences, and a permanent growing of the total amount of population and, accordingly, a higher level of lifespan. In other words, IHP is the basis of the universal potential, which, in the course of time, is transformed into human capital.

The main difference between universal potential and human capital is the fact that human potential can change explosively, going up or down due to mile stone discoveries and inventions, political, economic and social changes, ecological disasters and pandemics. 
The human capital approach to a plethora of economic and social phenomena boosts a widely spread research direction nowadays. This paper provides an exploratory attempt of Shultz's theories to comparative and contrastive studies of the human capital. Accumulated universal capital unlike IHP changes gradually and slowly in response to exogenous changes in the social and economic environment: it needs time to be converted into capital. Shultz's concepts of human capital impact on social and economic structures look like conventional models of the diffusion of innovation.

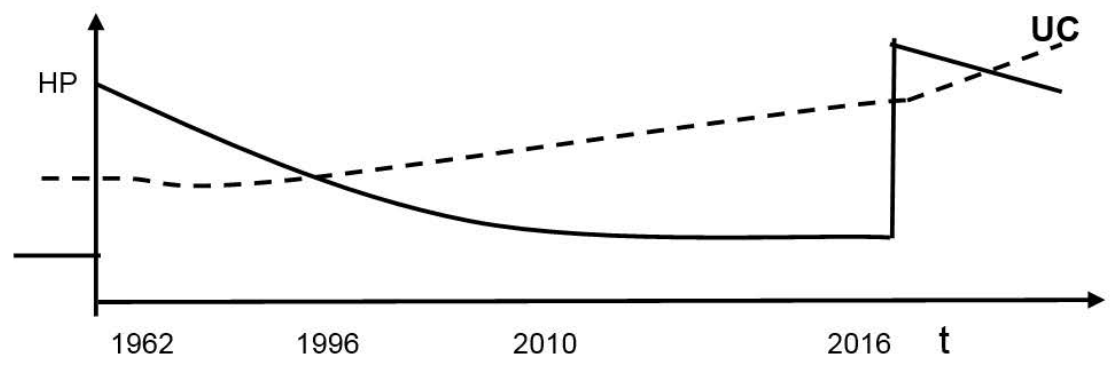

Fig. 3. Logistic curves of human potential (HP) and universal capital (UC) in the course of time (e.g. after nanomaterials invention). The 6-th Way Technology is shown after 2016.

This is the time of neuromaterials and artificial intellect.

Danilenko argues the Nano diamonds were invented in 1962, fullerenes and nanotubes - in 1996, graphenes - in 2010 [12]. Due to these inventions and discoveries people received a powerful universal potential which in approximately 60 year time transform it into the universal capital through further growth and development of new nanomaterials and concomitant nanotechnologies. According to Glazyev's views, humankind is in the 5-th way technology era [13]. After a revolutionized breakthrough of the Noble Prize winners in Chemistry 2016, Jean-Prierre Sauvage, Sir J. Fraser Stoddart and Bernard L. Feringa, jointly awarded for the design and synthesis of molecular machines, chemistry was taken to a new dimension [14]. Accordingly, humankind has been provided with a jump and transition to the 6-th way of technological development - the epoch of neuromaterials and artificial intellect.

\section{ACKNOWLEDGEMENTS}

The research has been conducted due to granting funds for interdisciplinary research projects under the Russian Foundation for Basic Research (RFBR) jointly with the Government of the Krasnoyarsk Krai. The Project № 18-413-242002 "Polyparadigm and multiethnic approaches to the quality evaluation of population living standards as an instrument of the human potential development of a macro region "Enisseyskaya Sibir" (The Enissey Siberia)".

\section{REFERENCES}

[1] T.W. Shultz, "Investment in Human Capital", The American Economic Review, no 1 (2), pp. 1-17, 1961.

[2] G.S. Becker, Human Capital, N.Y.: Columbia University Press, 1964.

[3] Yu.A. Korchagin, "Russian Human Capital: Is it a Factor of Development or Degradation?" Voronezh: CIRE 2005. Retrieved from URL. http://www.lerc.ru/?part=books\&art=5 (in Russian).

[4] Oil Price Dynamics. Retrieved from URL. http://usdkurs.ru/dinamica-cen-na-neft.htm (in Russian).

[5] A.V. Lulishin, "Negative Human Capital: Social and Economic Aspects", Russia and Europe: Culture and Economics Connectedness, pp. 326-328, 2014 (in Russian).

[6] O.V. Etilina, V.I. Kirko, E.V. Malakhova, "Human Capital Development of the Indigenous People of Northern and Arctic Territories, Journal of the Consumer Cooperation University, no. 1, pp. 106112.

[7] V.I. Kirko, E.A. Evseenko, E.V. Malakhova, A.I. Shadrin, "Quality of life evaluation by the indigenous population of the arctic north of the Krasnoyarsk territory (Krai) based on Khatanga rural population", Journal of Siberian Federal University: Humanities, vol. 11, no 10, pp. 15471571, 2018. 
[8] V.I. Kirko, E.A. Evseenko, E.V. Malakhova, N.P. Koptseva, "Career choices made by middle and high schoolchildren with the main focus on representatives of indigenous peoples of the north in the republic of Sakha (Yakutia)", Journal of the Novosibirsk State Pedagogical University, vol. 7, no 6, pp. 7-25, 2017.

[9] A. Kuzhuget, V. Kirko, A. Lukyanova, V. Razumovskaya, "Morphofunctional characteristics of the indigenous people teenagers at the age of 15-18 years old in the Sakha Republic (Yakutia, Russia)", Proceedings of the 6-th SWS International Scientific Conferences on Social Sciences, pp. 35-42, 2019.

[10] O.E. Kondakova, S.N. Shilov, B.I. Kirko, "Psycho-Physiological and Adaptive Characteristics of Children and Teenagers Residing in the Northern Territories", Journal of Siberian Federal University: Biology, vol. 10, no 3, pp. 312-322, 2017.

[11] Minority Northern Ethnic Peoples' Health. Retrieved from URL. http://www.hintfox.com/article/zdorove-malochislennih-narodov-severa.html

[12] V.V. Danilenko, "From the History of Nano diamonds Synthesis Invention", Physics of Solids, vol. 46, no 4, pp. 581-584, 2004.

[13] S.Yu. Glazyev, "World Economic Crisis as a Process of Economic Ways Change", Economics Issues, no 3, pp. 26-34, 2009.

[14] S.Yu. Glazyev, "Prospects of Formation of the New 6-thTechnological Way" 